\title{
Techno-Economic Study of PV System for Household Electricity Generation in Almadinah AlMunawwarah
}

\author{
Khaled S. Al Qdah \\ Faculty of Engineering, Mechanical Engineering Department, Taibah University, Madinah 42435, KSA
}

\begin{abstract}
The aim of this work is to study the technological feasibility and economic viability of the electrification of small house lies in a farm 50km far away from Almadinah AlMunawwarah. Nowadays, solar powered air conditioning has witnessed an increased progress because air conditioning system is almost a must in every building in Saudi Arabia where the outside temperature in summer higher than $45^{\circ} \mathrm{C}$. therefore, this paper consists of two parts: one to investigate the design and performance of solar powered air conditioning system as a case study integrated with photovoltaic (PV) system which consists of PV panels, solar charger, inverter and batteries. The second part is to study the feasibility to provide electricity for a farm lies in the remote area far $50 \mathrm{~km}$ from Almadinah. The first step in this project is the load calculations for the selected space including lighting, cooling and other necessary appliances. Based on the cooling load calculations for the specified room used as a case study, it was found the estimated cooling load about 1-ton refrigeration $(3.52 \mathrm{~kW})$, the photovoltaic (PV) system has been constructed and built with the necessary connections. Data logging system has been used to measure the temperatures at the main components in the cycle. The input powers for the system as well as the coefficient of performance (COP) for the system under Almadinah climatic conditions were measured along the day. The COP varies between 2.16 to 4.22 for the system and are in a good agreement with conventional system performance. Economically, the PV system found to be the optimal solution to provide the required load at an initial cost of 187,267 SR. The present work shows that the PV system has the potential to provide electricity for remote homes far from the grids with additional environmental benefit that otherwise not gained when using conventional fossil fuel
\end{abstract}

Keywords: Performance; PV; COP; Remote Areas; Climatic Conditions

\section{Introduction}

Saudi Arabia is blessed with an abundance of solar energy which is evident from the annual average solar irradiance shown in figure 1 about $2400 \mathrm{kWh} / \mathrm{m}^{2}$ which is one of the highest in the world. Remote areas which pose problems to rural energy management and development because of poor road links with the urban centers, and remoteness from the national electrical transmission grid. Such remote communities are characterized by non-easy access to fuel resources, no access to central grid, low demand and low population. Indeed, these are ideal situations for considering the PV as an electricity source.Due to the increase in electricity demand worldwide it is becoming more common for cities to cut their power consumption through self-generation from renewable energy sources such as solar and wind to produce electricity. Photovoltaic technology represents a good solution for the problems of electricity in remote areas in Saudi Arabia and in similar countries where the daily average solar radiation is higher than $7 \mathrm{kWh} / \mathrm{m}^{2}$. Moreover, the fact that the higher power consumption occurs at the period of availability of maximum,

${ }^{*}$ Corresponding author. Tel.: +966568557421

E-mail: dr.khaled_qdah@yahoo.com,kqdah@taibahu.edu.sa

(C) 2017 International Association for Sharing Knowledge and Sustainability

DOI: $10.5383 /$ ijtee.14.01.007 daily solar energy in the year where the PV system is working at its best conditions, make the use of PV systems very advantageous especially in a higher power consumption device like air conditioning systems. In the last decade the energy consumption for cooling has increased dramatically in Saudi Arabia. The main reasons for this increasing energy demand for summer air- conditioning are the population growth, increased living standards and comfort demands as well as type of architecture; this increasing demand is one of the most significant costs to Saudi Arabia households during summer. In remote Saudi's villages, far from the grids, electric energy is usually supplied by diesel generators. In most of these cases, the supply with diesel fuel becomes highly expensive.

Therefore, this work consists of two parts, the first one focuses in the design and construction of solar powered air conditioning system integrated with photovoltaic (PV) system and the second part to investigate the feasibility to utilize PV system as a power source to provide electricity to the farm with a small house used as living rooms for the workers in this farm. To use PV for electricity generation, full cost analysis for the construction, installation and operation of solar system should be conducted. 


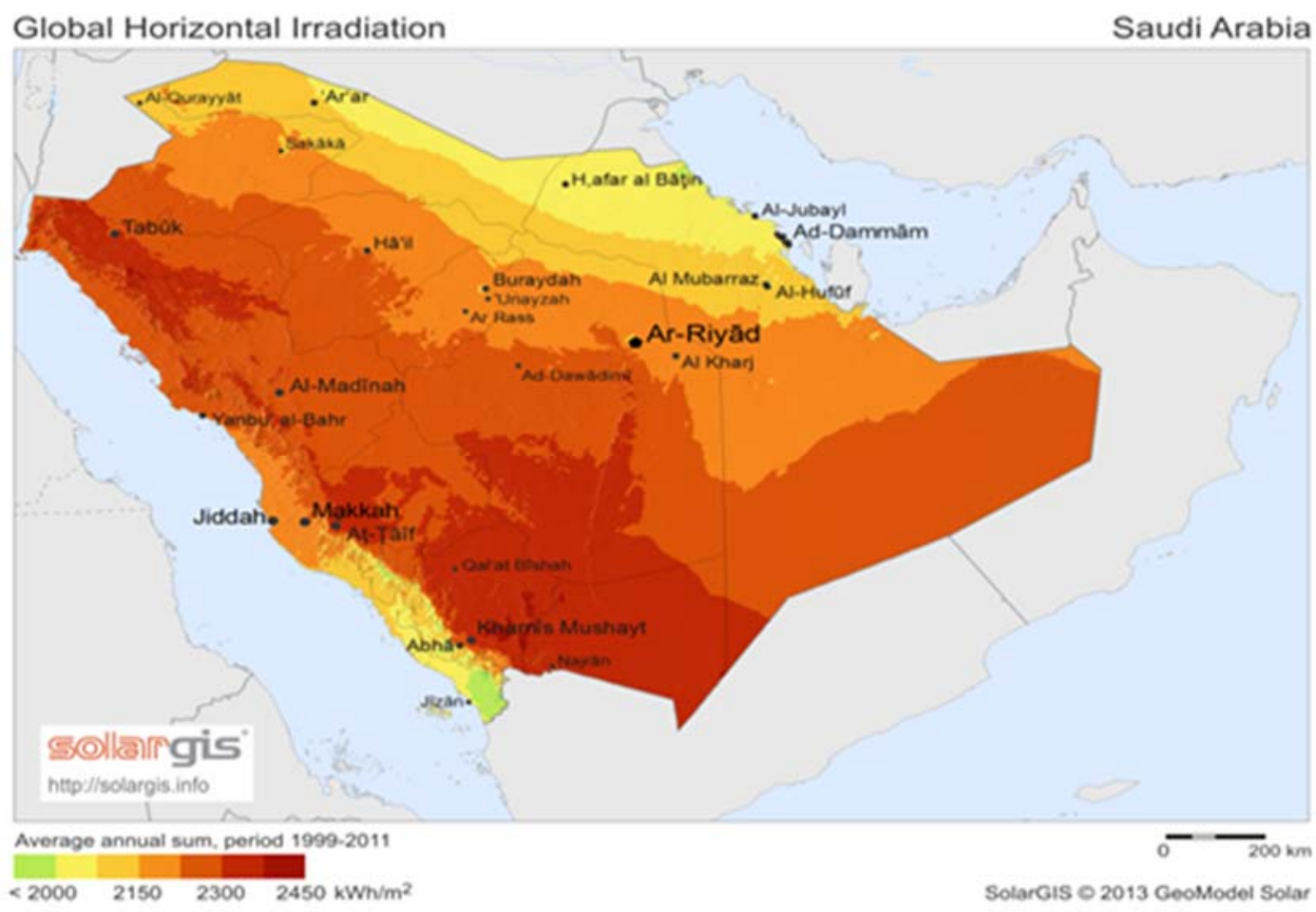

Figure 1: Annual Solar radiation map for Saudi Arabia

A lot of research is being conducted for this purpose especially in countries where there is high availability of solar energy just like Saudi Arabia and the most previous work that conducted solar air conditioning are as follow: Techno -economic studies for solar energy powered systems used for domestic applications has been conducted .Sayigh, 1981 carried out a performance comparisons for a hot, arid climate like that of Riyadh, Saudi Arabia are made for four solar air conditioning systems [1]. Bong, 1987 designed a solar-powered airconditioning system and have, installed and operated in Singapore [2]. Yeung, 1992 studied the feasibility of utilizing solar power for comfort cooling in Hong Kong [3]; a solarpowered absorption air-conditioning system was designed and successfully constructed on the campus of the University of Hong Kong. Tsilingiris, 1993 conducted the development of a theoretical microcomputer model suitable for performance predictions and investigation of the operational behavior of a simple solar cooling system for small residential applications [4]. Li and Sumathy, 2000 reviewed solar powered airconditioning systems with the absorption air of lithium bromide and water. A number of attempts have been made by researchers to improve the performance of the solar applied air conditioning (chiller) subsystems [5]. Madrose and Sayigh, 2007 conducted the theoretical behavior of thermal parameters and their interaction in absorption cooling systems powered with solar energy [6]. Umberto etal, 2009 analyzed the technical and economic feasibility of solar absorption cooling systems, designed for two different application fields: industrial refrigeration and air conditioning [7]. Naukkarinen, 2009 discussed the solar air conditioning and its role in alleviating the energy crisis of the Mediterranean hotels [8]. Dan etal, 2012 the potential applications and advantages of powering solar air-conditioning systems using concentrator augmented solar collector [9]. Lavinia and Mario, 2012 investigated the solar heating and air-conditioning by GSHP coupled to PV system for a cost effective high energy performance building [10]. Al-Salaymeh et al, 2009, the feasibility of utilizing the photovoltaic solar cells in an apartment in Amman city is studied and economic analysis of the system is performed [11]. Shaniqua Rahman and Al-Had rami, 2009 studied a PV-diesel hybrid power system with battery backup for a village being fed with diesel generated electricity to displace part of the diesel by solar [12]. Shaahid and El-Amin, 2009 analyzed solar radiation data of Rafha, K.S.A., to assess the techno-economic feasibility of hybrid PVdiesel-battery power systems to meet the load requirements of a typical remote village Rawdhat Bin Habbas) with annual electrical energy demand of 15,943Â MWh [13]. Gobind, 2014 presented a comparative assessment of the near term economic benefits of grid-connected residential PV systems. Case studies from the UK and India are taken as examples, as they vary significantly in solar resource, customer demands, electricity prices and financial support mechanisms [14.]. Shaahid and Elhadidy, 2008 analyzed the long-term solar radiation data of Dhahran to assess the techno-economic feasibility of utilizing hybrid PV-diesel-battery power systems to meet the load of a typical residential building [15]. Gang Liu et al., 2012, investigated the economic, technical and environmental performance of residential PV system running under the Queensland (Australia) climatic conditions, and optimize the size and slope of PV array in the system [16]. Blackleged, 2012 evaluated the viability of installing photovoltaic (PV) systems in existing commercial buildings in Dublin. Data collected from previously installed photovoltaic systems at the Dublin Institute of Technology was analyzed in order to determine the potential solar resource available in Ireland [17]. 
From the previous work, very little work has been conducted in western areas of Saudi Arabia regarding PV system and solar powered air conditioning in these areas which is the motivation and the aim of this work.

\section{Materials and Method}

The space under consideration is a house with an approximated area of $150 \mathrm{~m}^{2}$ lies in the northern part of Almadinah and is about $50 \mathrm{~km}$ far from the city center where Almadinah lies between Latitude $28,4^{\circ}-33,30^{\circ} \mathrm{N}$ and between Long. $35^{\circ}-39^{\circ}$ E. Table 1 summarizes the daily electricity consumption during summer calculated using the soft code prepared by Saudi Electricity company for lighting, water pumping used for irrigation, air conditioning, refrigerators and other extra domestic equipment in this house where the house consists of three rooms, one kitchen one bath room, a hall and the farm surrounding. The actual case study applied in this work is to examine the potential of using PV panels to generate electricity for one of these available air conditioning systems in the remote area near Almadinah. Many tools are available for sizing the PV system with battery storage. The steps below summarize the methodology to install PV system to operate the air conditioning system.

\subsection{Data collection}

The experimental works started by collecting the solar information such as design temperatures, humidity, tilt angle, daily and annual values of solar radiation for the site and the number of working hours. The space that has been chosen to be cooled in this work is the room with dimensions of $4 \times 4 \times 3 \mathrm{~m}$ used by the workers in the farm. The first step to size the air conditioner is the cooling load estimation for this selected space.

\subsection{Cooling load estimation for air conditioning system} Cooling load includes the type and the amount of cooling needed. Firstly, The chosen space will be cooled for eight working hours a day. Hourly analysis program (HAP) used, this program used to calculate the cooling load for any location. Secondly, the site must be specified as well as the inside and outside design temperature, relative humidity, thickness and type of insulation materials used and the building structure. Thirdly, the design temperatures used are $45^{\circ} \mathrm{C}$ as a maximum temperature during summer and the inside temperature is $23{ }^{\circ} \mathrm{C}$ and the relative humidity of $50 \%$ [18]. Finally, the output of the program will be displayed for each month. Figure 2 displays the maximum and minimum cooling load for this space during August. It was found that the maximum cooling load during August is about $3.4 \mathrm{~kW}$ whereas the minimum cooling load during January is $2.4 \mathrm{~kW}$.

\subsection{Design and sizing the air conditioning system}

Based on cooling load calculations, the air conditioning unit has been selected with the following specification: unit capacity $3.52 \mathrm{~kW}$ or 1-ton refrigeration (1TR) split unit, $220 \mathrm{~V}$, input power $1.250-1.374 \mathrm{~kW}$.

\subsection{PV system sizing and material selection for all the farm} Based on air conditioning unit capacity that has been selected under Almadinah climatic conditions and the data collected, where the daily intensity of solar radiation about $7.5 \mathrm{kWh} / \mathrm{m}^{2}$, the PV solar powered system specifications can be selected and design. From table 1, it can be seen that the total daily load $116.17 \mathrm{kWh}$ using the software prepared by Saudi Electricity Company. Figure 3 shows that the air conditioning load forms about $52 \%$ of the full load needs for the farm which is the motivation for this work where the summer peak load in all Saudi cities as a result to the air conditioning running too long time. Table 1 summarized the daily, monthly and annual load for each equipment used in this farm and the annual total cost

Table 1: Daily, monthly and annual Power consumption for all appliances

\begin{tabular}{llllllll}
\hline No & Applications & Power (W) & $\begin{array}{l}\text { No } \\
\text { off }\end{array}$ & $\begin{array}{l}\text { Working } \\
\text { hours }\end{array}$ & $\begin{array}{l}\text { Daily } \\
\text { Consumption } \\
\text { kWh }\end{array}$ & $\begin{array}{l}\text { Monthly } \\
\text { Consumption } \\
\mathrm{kWh}\end{array}$ & $\begin{array}{l}\text { Annual } \\
\text { Consumption } \\
\mathrm{kWh}\end{array}$ \\
\hline 1 & Neon bulb & 60 & 6 & 8 & 2.88 & 86.4 & 1036.8 \\
\hline 2 & Neon bulb & 60 & 4 & 4 & 0.96 & 28.8 & 345.6 \\
\hline 3 & Neon bulb & 60 & 4 & 6 & 1.44 & 43.2 & 518.4 \\
\hline 4 & Neon bulb & 60 & 2 & 4 & 0.48 & 14.4 & 172.8 \\
\hline 5 & Blub & 60 & 2 & 4 & 0.48 & 14.4 & 172.8 \\
\hline 6 & Blub & 100 & 18 & 8 & 14.4 & 432 & 5184 \\
\hline 7 & Refrigerator & 100 & 1 & 24 & 1.68 & 50.4 & 604.8 \\
\hline 8 & Water Heater & 500 & 2 & 3 & 2.1 & 63 & 756 \\
\hline 9 & Air Conditioner & $2 \mathrm{TR}$ & 1 & 4 & 12.8 & 384 & 4608 \\
\hline 10 & Air Conditioner & $1 \mathrm{TR}$ & 3 & 10 & 48 & 1440 & 17280 \\
\hline 11 & Water Pump & 100 & 18 & 10 & 18 & 540 & 6480 \\
\hline 12 & Water Pump & 100 & 3 & 10 & 3 & 90 & 1080 \\
\hline 13 & Extra Loads & 100 & 10 & 1 & 10 & 300 & 30 \\
\hline Total Consumption & & & & & $116.17 \mathrm{~kW}$ & 3485.16 & $3162 \mathrm{SR}$ \\
\hline Total Cost (SR) & & & & & & \\
\hline
\end{tabular}




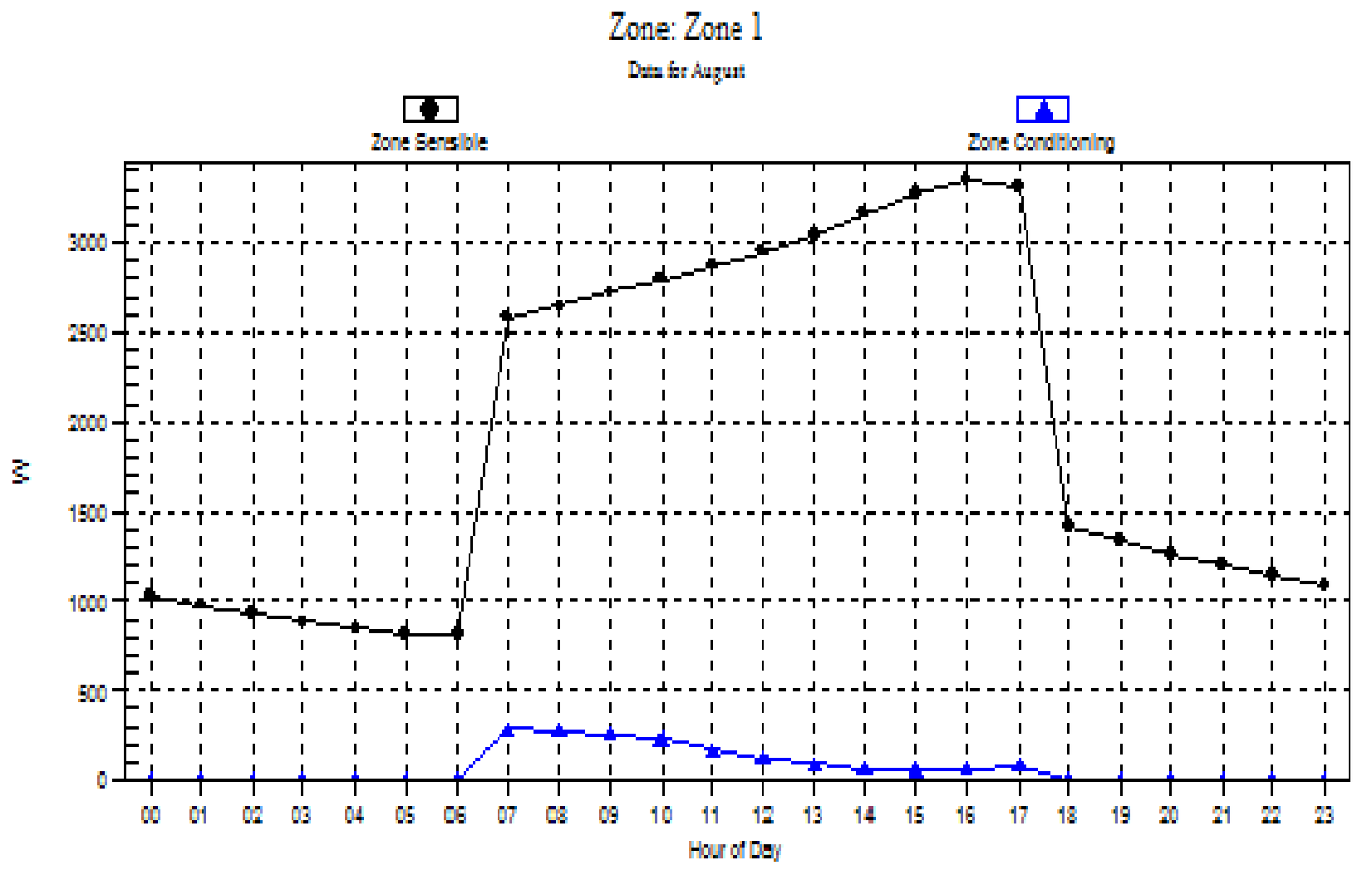

Figure 2: Maximum cooling load estimated in August, 2015

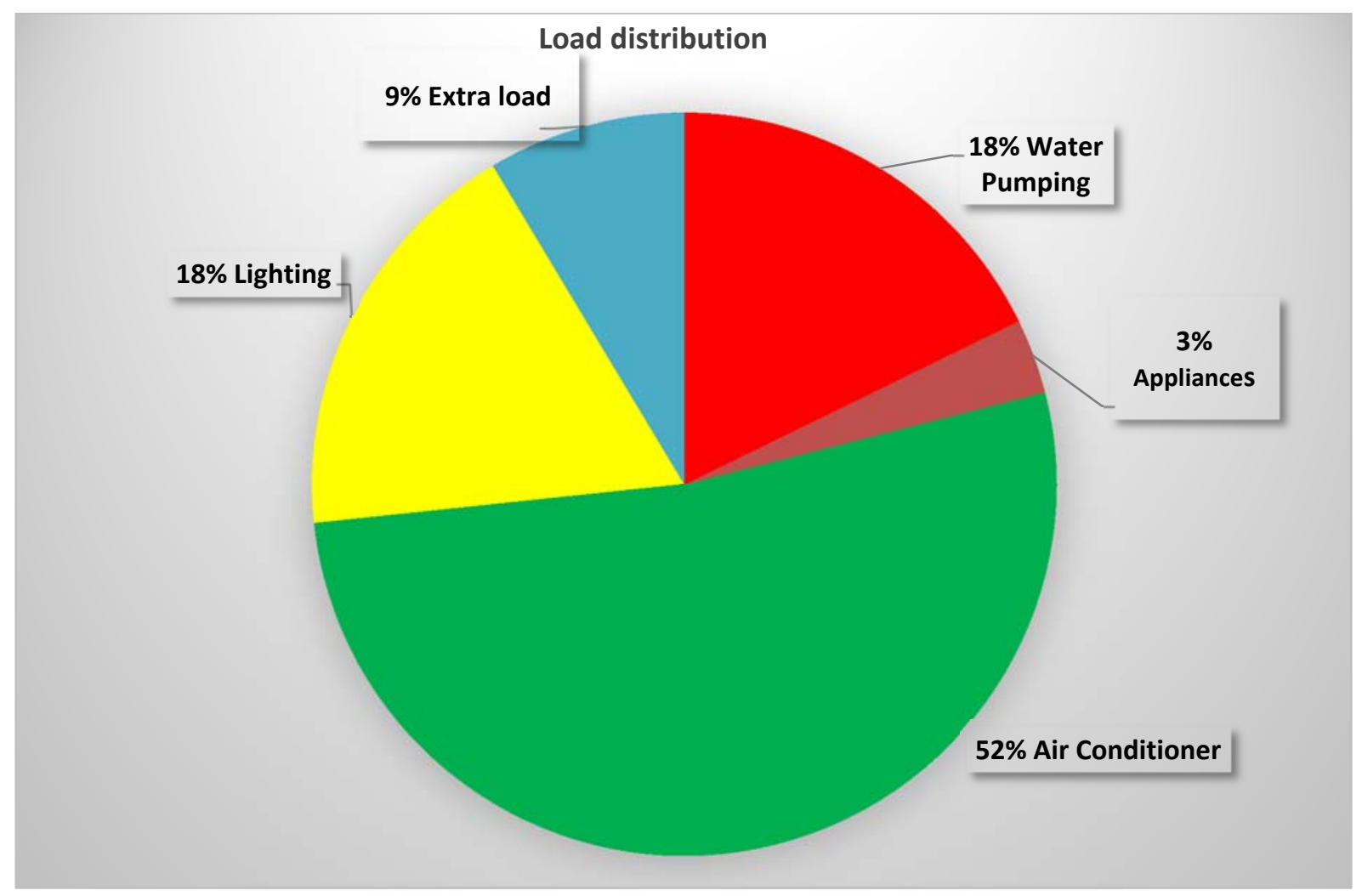

Figure 3: Load distribution for all appliances used in this investigation 


\subsection{PV installation and Tilt angle selection}

In order to make the system work efficiently, the inclination angle for the panels should be carefully selected. The optimum tilt varied from month to another and the collected solar energy depends on the optimum panel tilt for each month. It was found that the average optimum tilt angle at Madinah for the winter months is $37^{\circ}$ and for the summer months is $12^{\circ}$. So, the yearly average tilt panel is $23.5^{\circ}$ which nearly corresponding to the latitude of Madinah site $24.5^{\circ}$ [22]. After the PV panels been selected along with the batteries, charge controller and inverter, the basement and suitable, cabinets are used to store and protect the system. The system installed as shown in figure 4. This figure shows the actual system that includes the air conditioning unit and the PV panels in addition to the necessary devices like charge controller and invertor

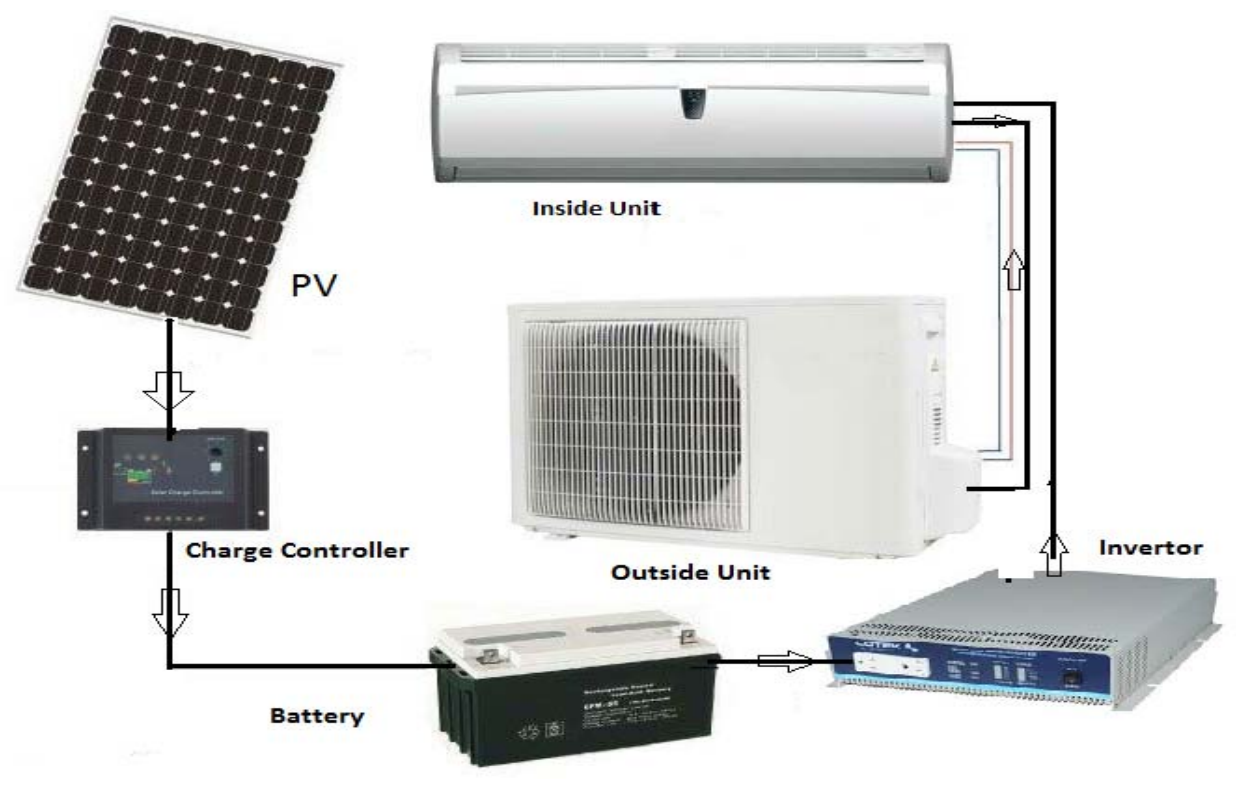

Figure 4: Actual solar powered air conditioning system

\section{Results and Discussion}

From figure 3 shown previously, we see that the air conditioning system consumes about $52 \%$ of the total load of the building. The system performance is assessed by measuring the temperature at each previous component in the cycle by using data logging system connected with thermocouples. To find the coefficient of performance, the main properties for the working fluid which are; temperature, pressure, enthalpy and entropy must be reported. Figure 5 represent the variation of COP with time during last June, it can be seen that the higher value of COP measured in the morning where the outside temperature still low and the system is fully charged. The same trend can be seen in the figure through July where the summer takes place and the outside temperatures higher than $40^{\circ} \mathrm{C}$. the COP is a function of compressor input work and the desired output, the higher values indicated that the cooling capacity is at its optimum values during the first hours then the compressor needs more work which means lower COP. It can be considered that the COP with its normal ranges for these types of air conditioning system powered by conventional power systems. Figure 6 shows the variation of temperatures with time in the afternoon from $1 \mathrm{pm}$ to $5 \mathrm{pm}$ at the beginning of June where the outside temperature 40 ${ }^{\circ} \mathrm{C}$, the compressor usually switch off by the control system when the cooled space temperature reaches $23^{\circ} \mathrm{C}$. A small deviation between the inlet of compressor and evaporator temperature is present during this test which is due to outside temperature variation and the continuous door opening for the room from the occupants. From the results obtained using solar energy as a power source, it can be said that solar air-conditioning might be a way to reduce the demand for electricity. At the moment, PV module manufacturers usually provide performance warranties of 30 years, with maximum power loss of no more than $20 \%$ at the end of the 30 years. Because of the effects that climatic conditions have on the performance of PV systems, continuous monitoring under outdoor conditions is thus very important in assessing the actual field performance loss. 


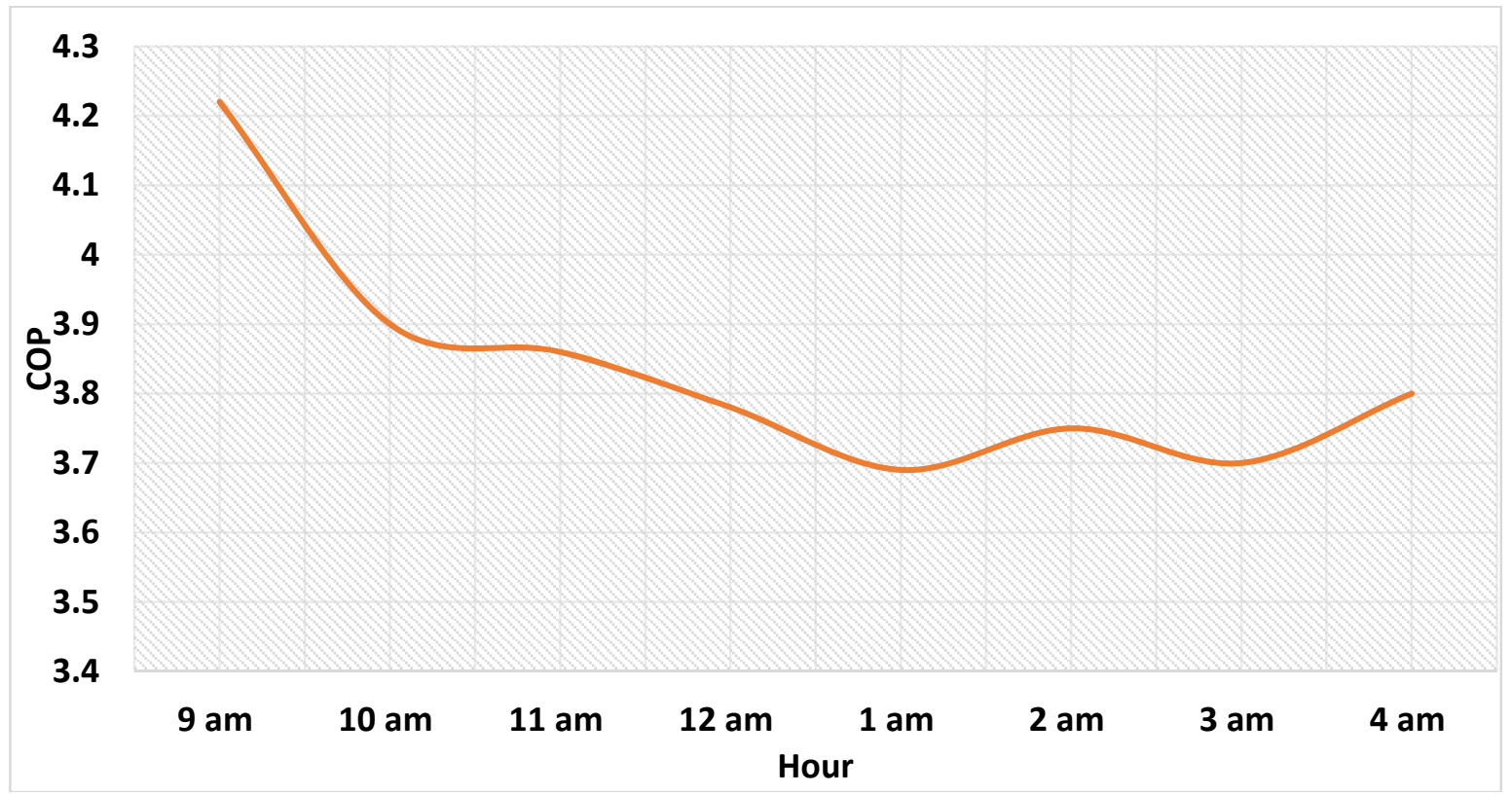

Figure 5: Variation of the coefficient of performance during summer days

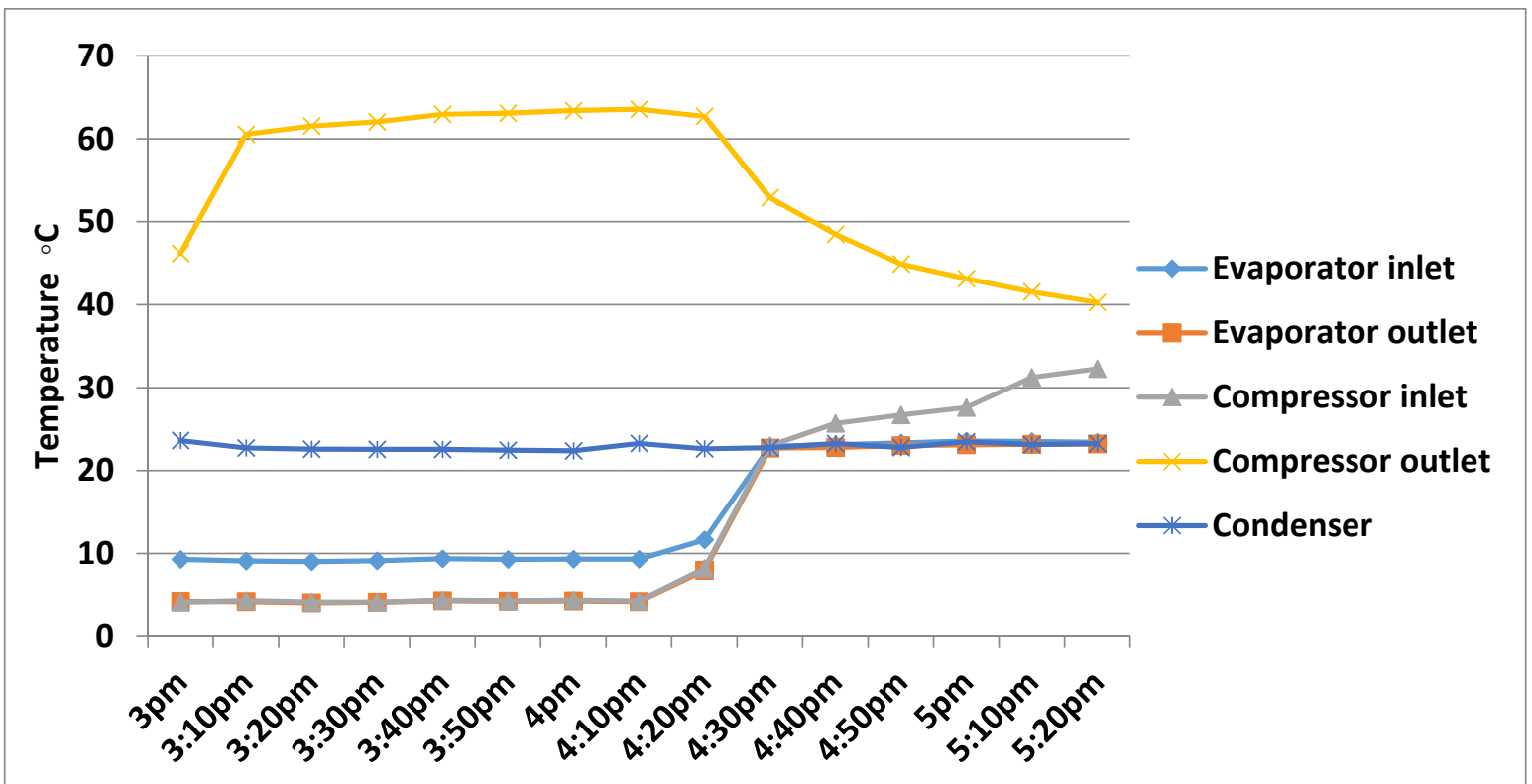

Figure 6: Temperature variations from 1:00 pm to 5:00 pm during June,2015. 


\section{Cost analysis}

Table 2 summarizes the total cost for all the equipment used to provide electricity for the farm by PV system including system installation and construction work and the present worth for the batteries. From this table, the total cost about 187,267 SR. which can be considered too high because the electricity price still low in Saudi Arabia compared with the other countries. The present worth $(\mathrm{PW})$ for the batteries after $\mathrm{N}$ years is estimated according to [11] and is expressed as:
Where A presents the value for the batteries which is 17280 SR. $\mathrm{i}$ is the imposed inflation rate $(6 \%)$, and $\mathrm{N}$ is the number of years, and $\mathrm{d}$ is the discount rate $(10 \%)$. The present worth for the first 10 years is $P W=\frac{17280(1+0.06)^{9}}{(1+0.1)^{10}}=11255.626 \mathrm{SR}$ and for the next 10 years will be $7331.546 \mathrm{SR}$. The longer payback period refers to the low electricity price now but it is expected that these prices will be increased as a result of oil fluctuating prices. The payback period for installation the full system varies between 59 to 3.9 year depends on the annual increasing in the electricity prices as shown in figure 7.

$$
P W=\frac{A(1+i)^{N-1}}{(1+d)^{N}}
$$

Table 2: Summary of PV system total cost

\begin{tabular}{cccc}
\hline Item & No off & Unit price (SR) & Total (SR) \\
\hline PV Panels & 48 & 1750 & 84000 \\
Batteries & 36 & 480 & 17280 \\
Charge controller & 8 & 1400 & 11200 \\
DC-AC Inverter & 8 & 4400 & 35200 \\
Construction work & 1 & 12000 & 12000 \\
Cables and connections & 1 & 5000 & 5000 \\
Labor rate & 2 & 2000 & 4000 \\
Batteries Present worth & 1 & 18587 & 18587 \\
\hline Total & & $\mathbf{1 8 7 , 2 6 7}$ \\
\hline
\end{tabular}

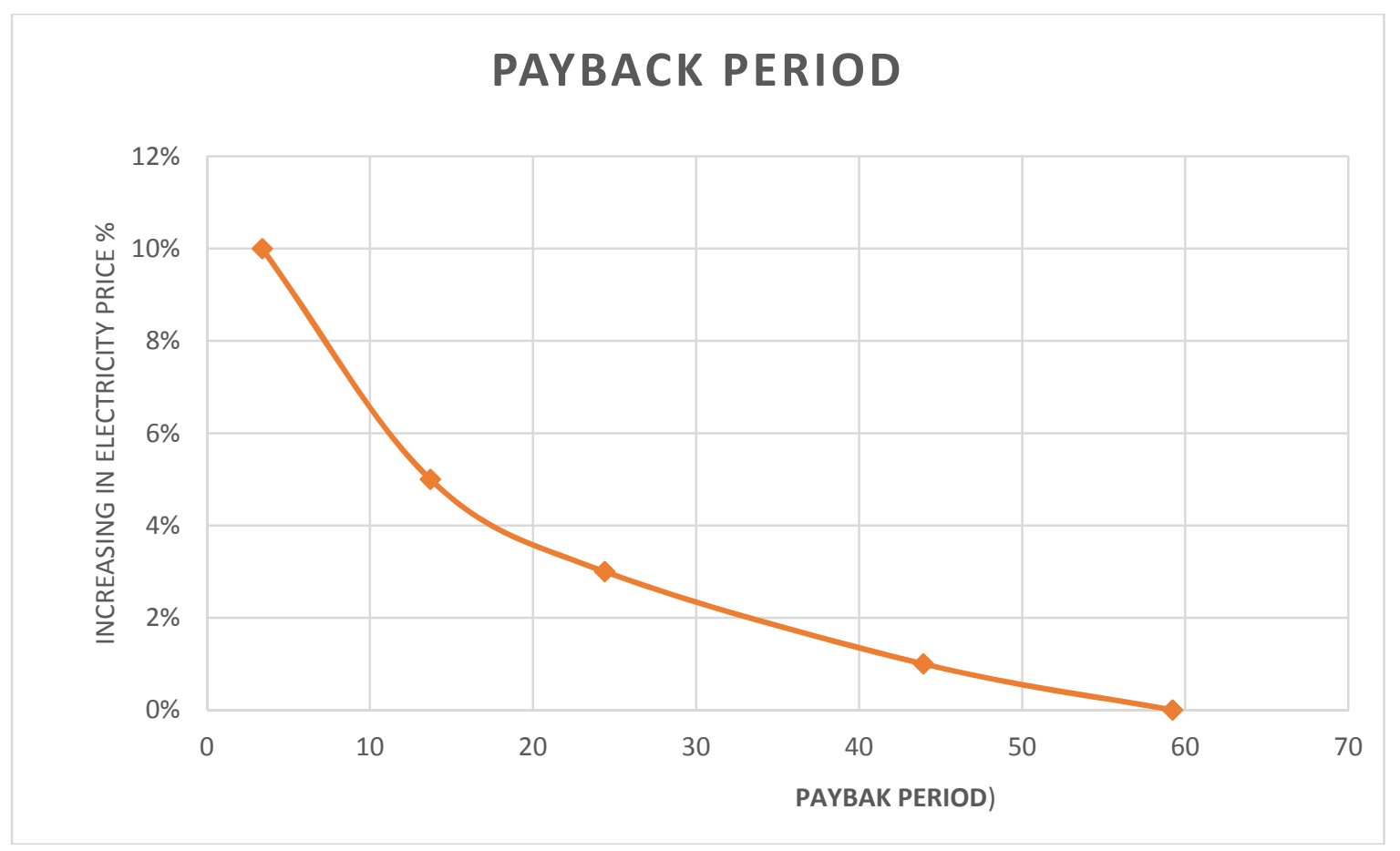

Figure 7: Variation of payback period with electricity price 
Solar air conditioning at an economically competitive level could reduce electricity costs for residential and small buildings and this would cut the growth of peak electric demand. About $70 \%$ of the power used in Saudi Arabia in the summer time goes into air conditioning (according to Saudi Electricity Company). The approximate cost can be considered high when we compare it with electricity price in Saudi Arabia. Recent price drops of PV panels however have changed so the system can be utilized efficiently in remote areas where the cost of electricity generation becomes too high. In spite of the high cost, long payback period, the solar energy as a power source to the air conditioning in remote areas is considered one of the few solutions to overcome the summer high demand and addresses peak loading. On hot summer days, the electricity grid increasingly faces the danger of overload due to air conditioner use in addition to its advantages as a clean and safe energy. The air conditioning system can be operated on solar and can be used in non- electrified areas as well as it is environmentally friendly. To encourage the off grid residence with this source of clean electricity the Saudi Electricity Company starts to facilitate this integration; The government start supporting the farmers to use alternative energy sources because the cost of installation an electrical station to provide this farm with electricity is too cost and the real cost estimation shown in table 3. Compared with utilizing solar system and in addition to difficulties to use other conventional sources. Installation power station will cost about 847,200 SR [23] in addition to the operating and maintenance cost. The payback period for this connection is $847200 / 187267=4.52$ years.

The overall prices of the renewable energy is rather high until this day, however prices continue to fall, and probably the overall price will drop at least $30 \%$ during the next 5 years based on the fast improvement for PV modules. This becomes the best scenario to supply electricity to the remote areas.

Table 3: Cost of installation and connections to electricity grid by SEC small power

\begin{tabular}{lcccl}
\hline \multicolumn{1}{c}{ Item } & $\begin{array}{l}\text { No } \\
\text { off }\end{array}$ & $\begin{array}{c}\text { Unit cost } \\
\text { (SR) }\end{array}$ & Total cost & Details \\
\hline Poles ( Columns) & 72 & 4000 & 288000 & 6 km each km needs 12 poles (72 poles) \\
Cables, crossers and connections & 12 & 40000 & 480000 & Each set for 500 m only and we need 12 sets \\
$\begin{array}{l}\text { Civil construction and technician } \\
\text { work }\end{array}$ & 72 & 700 & 50400 & 700 SR for each pole we have 72 poles \\
$\begin{array}{l}\text { Regular fees for new connection } \\
\text { Transformer cost }\end{array}$ & 1 & 3800 & 3800 & \\
( Power Unit) & 1 & 25000 & 25000 & 33000 KVA- 1000 KVA (380/220 V) \\
\hline Total Cost & & & & \\
\hline
\end{tabular}

\section{Environmental Evaluation}

Summer peak load which is the period of maximum demand for electricity in Saudi Arabia increased by $6.7 \%$ from 2013 to 2014 where summer temperatures exceed $45{ }^{\circ} \mathrm{C}$. This period tends to span the months of May and September, when air conditioning use it also at its highest. This will increase the percentage of fuel consumption to generate electricity and leads to more emissions. The Saudi Arabia 2014 annual $\mathrm{CO}_{2}$ emissions estimates (in thousands of $\mathrm{CO}_{2}$ tonnes) along with a list of emissions per capita (in tonnes of $\mathrm{CO}_{2}$ per year) from same source is 944000 and 16.8 per capita. The data only considers carbon dioxide emissions from the burning of fossil fuels [24]. Also, Saudi Arabia ranks one of the highest among nations based on 2008 fossil-fuel $\mathrm{CO}_{2}$ emissions with 118 million metric tons of carbon [24].

On November 2015, Saudi Arabia submitted its Intended Nationally Determine Contribution (INDC), seeking to reduce its emissions annually by up to $130 \mathrm{MtCO} 2 \mathrm{e}$ in 2030. The country will move faster to a non-oil based economy while contributing with greater effort to fighting climate change. In order to achieve this issue, the government encourage the research related to alternative energy which is any form of energy derived from non-conventional fuel sources including solar, wind, geothermal.

Solar energy systems including PV to generate electricity or thermal energy is the optimal solution because it is clean and don't harm the environment by producing toxic gases and don't contribute to greenhouse effects, renewable, economic on long run even its high initial cost, solar energy have no running cost and no monthly bill. The government announced the completion of the largest ground mounted PV system in the Kingdom of Saudi Arabia. The 3.5 megawatt (MW) system is owned by Saudi Aramco and installed on the grounds of the King Abdullah Petroleum Studies and Research Center (KAPSARC), the world's largest energy research center, in Riyadh. The grid connected system is designed to supply 5,800 megawatt hours of electricity per year and offset roughly 4,900 tons of carbon dioxide $\left(\mathrm{CO}_{2}\right)$ emissions per year. Now, solar power in Saudi Arabia has become more important to the country as oil prices have risen. and over $50 \%$ of electricity was produced by burning oil. At Almadinah region, the irradiation in this region is 
relatively high making it more economical and solar system may be produce 3 times the power produced from the same system in north Europe for example and this is the reason that we focused on PV system to provide electricity in spite of high initial cost to keep clean, safe environment

\section{Conclusions}

This paper studied the techno-economic feasibility of utilizing renewable energy in supplying electricity to a household in Almadinah AlMunawwarah remote areas. The existing house not connected to the grid and lies in a farm near Almadinah. The chosen option was a PV connected system. The electricity delivered by the grid is less expensive than PV scenario because the electricity prices in Saudi Arabia still low compared with the other countries. Experimental investigation has been carried out as a case study and the results indicated that the PV solar system to power air conditioners in remote areas is technically feasible while economically is challenged.

Although, the results obtained show long payback period but this will be reduced with the technology improvement on PV systems. Finally, the project comes as a solution to reduce the electric demand especially during the summer and can be used efficiently in remote area where the electricity is not available with clean and low emissions energy source since the government put forward a remarkable plan to reduce $\mathrm{CO}_{2}$ emission results from fuel burning used to generate electricity.

\section{Acknowledgments}

The author would like to express deep thanks and gratitude to the Deanship of Scientific Research at Taibah University for the technical and financial supports and encouragement

\section{References}

[1] A .Sayigh. Solar air conditioning in a hot arid climate. Proceedings of the Second Miami International Conference, Miami Beach, Fla, Vol.2 (1981), pp.761773.

[2] T.Y. Bong, Ng. K.C, Tay. A.O. Performance study of a solar-powered air-conditioning system. Solar Energy, Vol.39 (1987), pp.173-182.

[3] M.R. Yeung., Yuen. P.K., Dunn A., Cornish L.S. Performance of a solar-powered air conditioning system in Hong Kong. Solar Energy, Vol.48 (1992), pp.309-319.

[4] P.T. Tsilingiris. Theoretical modelling of a solar air conditioning system for domestic applications. Energy Conversion and Management. Vol.34, (1993), pp.523-531.

[5] Z.F.Li., K. Sumathy. Technology development in the solar absorption air-conditioning systems. Renewable and Sustainable Energy Reviews. Vol.4, (2000), pp.267-293
[6] A. Marderos, Sayegh. The solar contribution to air conditioning systems for residential buildings. Desalination Vol.209. (2007), pp.171-176.

[7] D.Umberto, P. Stefania, S. Paolo. Solar-powered cooling systems: Technical and economic analysis on industrial refrigeration and air-conditioning applications. Applied Energy. Vol.86, (2009), pp.1376-1386.

[8] P. Naukkarinen. Solar air conditioning and its role in alleviating the energy crisis of the Mediterranean hotels. International Journal of Sustainable Energy. Vol.28, (2009), pp. 93-100.

[9] D. Nchelatebe, N. Kwetta, M. Smyth. The potential applications and advantages of powering solar airconditioning systems using concentrator augmented solar collectors. Applied Energy, Vol.89, (2012), pp. 380-386.

[10] C.T. Lavinia, M. Mario, DP. Claudio. Solar heating and air-conditioning by GSHP coupled to PV system for a cost effective high energy performance building. Energy Procedia. Voi.30, (2012), pp. 683 - 692.

[11] A. Al-Salaymeh, Z. Al-Hamamre, Firas Sharaf. Technical \& Economical Assessment of the Utilization of Photovoltaic Systems in Residential Buildings: The case of Jordan. GCREEDER 2009, Amman-Jordan, March 31st - April 2nd 2009.

[12] S. Rehman, M. Luai. Al-Hadhrami. Study of a solar PV diesel battery hybrid power system for a remotely located population near Rafha, Saudi Arabia. Energy. Vol. 35, (2010), pp.4986- 4995.

[13] S.M. Shaahid, I. El-Amin. Techno-economic evaluation of off-grid hybrid photovoltaic-dieselbattery power systems for rural electrification in Saudi Arabia - a way forward for sustainable development. Renewable and Sustainable Energy Reviews. Vol. 13 (2009), pp. 625-633.

[14] G. Gobind. Pillai, A. Ghanim, Putrus, Tatiani Georgitsioti, M. Nicola. Pearsall. Near-term economic benefits from grid-connected residential PV (Photovoltaic) systems. Energy. Vol. 68 (2014), pp. 832-843.

[15] S.M. Shaahid_, M.A. Elhadidy. Economic analysis of hybrid photovoltaic-diesel-battery power systems for residential loads in hot regions-A step to clean future. Renewable and Sustainable Energy Reviews. Vol. 12, (2008), pp.488-503.

[16] L. Gang, M.G. Rasul, M.T.O. Amanullah, M.M.K. Khan. Techno-economic simulation and optimization of residential grid-connected PV system for the Queensland climate. Renewable Energy. Vol. 45, (2012), pp. 146-155

[17] J. Blackledge, M. Rivas Duarte, D. Joseph Kearney, E. Murphy. Techno-Economic Analysis of Photovoltaic System Design as Specifically Applied to Commercial Buildings in Ireland. Journal of Sustainable Engineering Design. Vol. 2, (2012), pp. 48-54. 
[18] R. McDowall. Fundamentals of HVAC Systems. American Society of Heating, Refrigerating and AirConditioning Engineers, Inc. and Elsevier Inc; 2007.

[19] S. Saad, I. Daut, M. Misrun, S. Champakeow and N. Ahmad. Study of Photovoltaic and Inverter Characteristics. University Malaysia Perlis (UniMAP). 2010.

[20] A. Shaari.S, A, Omar, S. Haris, S.I.Sulaiman and K.S. Muhammad. Solar Photovoltaic Power: Design and Installation of Stand-Alone Systems, Pusat Tenaga Malaysia; (2009), pp. 46-52.

[21] C. Borgnakke, R. E. Sonntag . Fundamentals of Thermodynamics, 7th edition, 2011. John Wiley.
[22] M. Benghanem. Optimization of tilt angle for solar panel: Case study for Madinah, Saudi Arabia. Applied Energy. Vol. 88, (2011), pp. 1427-1433.

[23] Saudi Electricity Company website. https://www.linkedin.com/company/saudi-electricitycompany.

[24] Boden, T.A., G. Marland, and R.J. Andres. 2011. Global, Regional, and National Fossil-Fuel CO2 Emissions. Carbon Dioxide Information Analysis Center, Oak Ridge National Laboratory, U.S. Department of Energy, Oak Ridge, Tenn., U.S.A. doi 10.3334/CDIAC/00001_V2011 